\title{
Adhesion Properties of Acrylonitrile-Butadiene Rubber/Standard Malaysian Rubber Blend Based Pressure-Sensitive Adhesive
}

\author{
B. T. Poh, J. Lamaming, and G. S. Tay \\ School of Industrial Technology, Universiti Sains Malaysia, 11800 Penang, Malaysia \\ Correspondence should be addressed to B. T. Poh; btpoh@usm.my
}

Received 7 January 2014; Accepted 19 February 2014; Published 24 April 2014

Academic Editor: Juan J. De Damborenea

Copyright (C) 2014 B. T. Poh et al. This is an open access article distributed under the Creative Commons Attribution License, which permits unrestricted use, distribution, and reproduction in any medium, provided the original work is properly cited.

\begin{abstract}
Viscosity and adhesion properties of NBR/SMR L blend based pressure-sensitive adhesive were investigated using coumaroneindene resin, toluene, and poly(ethylene terephthalate) (PET) as tackifier, solvent, and coating substrate, respectively. Coumaroneindene resin content was fixed at 40 parts per hundred parts of rubber (phr) in the adhesive formulation. The ratio of NBR/SMR L blend used was $0,20,40,60,80$, and $100 \%$ of NBR content. Four different thicknesses, that is, 30, 60, 90, and $120 \mu \mathrm{m}$, were used to coat the PET film. The viscosity of adhesive was determined by a Brookfield viscometer, whereas loop tack, peel strength, and shear strength were measured using a Lloyd Adhesion Tester operating at $30 \mathrm{~cm} / \mathrm{min}$. Result indicates that the viscosity, loop tack, and shear strength of blend adhesives increase with \% NBR. However, for peel strength, it indicates a maximum at $40 \%$ NBR blend ratio for the three modes of peel tests. In all cases, $120 \mu \mathrm{m}$ coated sample consistently exhibits the highest adhesion values compared to the other coating thicknesses, an observation which is associated with the higher volume of adhesive in the former system.
\end{abstract}

\section{Introduction}

Many studies on rubber-based adhesives involve a single component rubber as the elastomer in the adhesive formulation. These include the study of viscoelastic properties of natural rubber pressure-sensitive adhesive using acrylic resin as a tackifier [1], the effects of miscibility and viscoelasticity on peel strength and shear creep resistance of natural-rubberbased pressure-sensitive adhesives [2,3], and modelling the peel performance of natural rubber-based pressure-sensitive adhesives at different rates of testing $[4,5]$. Thitithammawong et al. [6] discussed the preparation and properties of chlorinated epoxidized natural rubber latex and its latexbased adhesives. On the other hand, Varghese and Thachil [7] studied the adhesive properties of neoprene-phenolic blends. However, study on the adhesive properties of rubberbased blends is rarely reported. Phillips et al. $[8,9]$ have studied the singlet oxygen generation and adhesive properties in polymer blends adhesives using block copolymers as the elastomers. Smitthipong et al. [10] investigated the selfadhesion of immiscible polyisoprene rubber-hydrogenated acrylonitrile butadiene rubber blends, whereas Magida et al. [11] reported the pressure-sensitive adhesive applications of compatible blend of styrene-vinyl acetate copolymer/natural rubber latex. Meanwhile, da Silva et al. [12] found that a single resin will improve the adhesion property of adhesive prepared from styrene-isoprene-styrene (SIS)/styrenebutadiene-styrene (SBS) mixtures. Kim et al. [13] showed that addition of styrene-ethylene-butylene copolymer increases the toughness and viscosity but decreases the lap shear strength of the hot-melt adhesives. Pichayakorn et al. [14] reported that blending of deproteinized natural rubber with several polymers improves the adhesive properties. On the other hand, Riyajan et al. [15, 16] studied the adhesion property of skim rubber/poly(vinyl alcohol) biodegradable pressure-sensitive adhesive. It was found that the optimal concentration of poly(vinyl alcohol) for a good adhesive was $20 \mathrm{phr}$. Recently, we have carried a few studies on the adhesion properties of SBR/SMR L and SMR 10/ENR blend adhesives [17-19]. Results indicate that adhesion properties strongly depend on the rubber blend ratio used. In view of the scarcity of research conducted on the adhesion behaviour of 
rubber-blend based adhesives, it is thus the aim of this paper to report some of our findings on the viscosity and adhesion properties of NBR/SMR L blend adhesives.

\section{Experiment}

2.1. Materials. One grade of natural rubber (SMR L) and one type of synthetic rubber (NBR) were used as the elastomers. SMR L and NBR were supplied by Rubber Research Institute of Malaysia and Bayer Company, respectively. The bound acrylonitrile content in NBR is $33 \%$. Glass transition temperatures for SMR L and NBR are $-72^{\circ} \mathrm{C}$ and $-40^{\circ} \mathrm{C}$, respectively. Coumarone indene resin was used as the tackifier. It was freshly supplied by Mukmin Enviro Company, Penang (Malaysia). Toluene was used as the solvent throughout the experiment.

2.2. Adhesive Preparation. The rubber was masticated using a 2-roll mill for 10 minutes. Different NBR/SMR L blends ratios, that is, $0 / 5,1 / 4,2 / 3,3 / 2,4 / 1$, and $5 / 0$ corresponding to 0,20 , $40,60,80$, and $100 \%$ NBR were used in the blend formulation. $30 \mathrm{~mL}$ of toluene was added into each rubber blend and stirred evenly. The solution was tightly closed and left for 24 hour to ensure complete dissolution. A fixed amount of $2 \mathrm{~g}$ of pulverized coumarone indene resin-corresponding to $40 \mathrm{phr}$ of resin-was added slowly to the solution with constant stirring. The resulting adhesives were left for 3 hours at room temperature $\left(30^{\circ} \mathrm{C}\right)$ before testing.

\section{Measurement}

3.1. Viscosity. A Brookfield viscometer (model DV-II + Pro) was used to measure the viscosity of the adhesives. Its speed was set at $1 \mathrm{rpm}$. The spindle (CPE-51) and metal cup (CPE$44 \mathrm{Y}$ ) were chosen in this testing. The platform and spindle head were cleaned with isopropyl alcohol. A drop of adhesive was put at the middle of the platform and testing was carried out for one minute. The average viscosity was recorded from at least five readings.

3.2. Tack. A PET film with dimension of $4 \mathrm{~cm} \times 25 \mathrm{~cm}$ was coated at the centre of the substrate $(4 \mathrm{~cm} \times 4 \mathrm{~cm})$ with different coating thickness using a SHEEN hand coater. The coated sample was conditioned at room temperature for 24 hours before testing. A loop was then formed and the adhesive coated area was gently brought into contact with a glass without any force other than the pushing force on the loop. The testing was conducted using a Lloyd Adhesion Tester (Model LRXPlus with NEXYGEN software) with a testing rate of $30 \mathrm{~cm} / \mathrm{min}$ to debond the loop from the glass plate. The average debonding force was recorded from the three highest peaks recorded in the test.

3.3. Peel Strength. Three types of peel test, namely, T-peel, $90^{\circ}$-peel, and $180^{\circ}$-peel tests were employed in this study. For the T-peel and $90^{\circ}$ peel test, the dimensions of the substrates were $20 \mathrm{~cm} \times 4 \mathrm{~cm}$. However, the dimensions of the substrate for $180^{\circ}$ peel test were $25 \mathrm{~cm} \times 4 \mathrm{~cm}$ and $15 \mathrm{~cm} \times 7 \mathrm{~cm}$. The

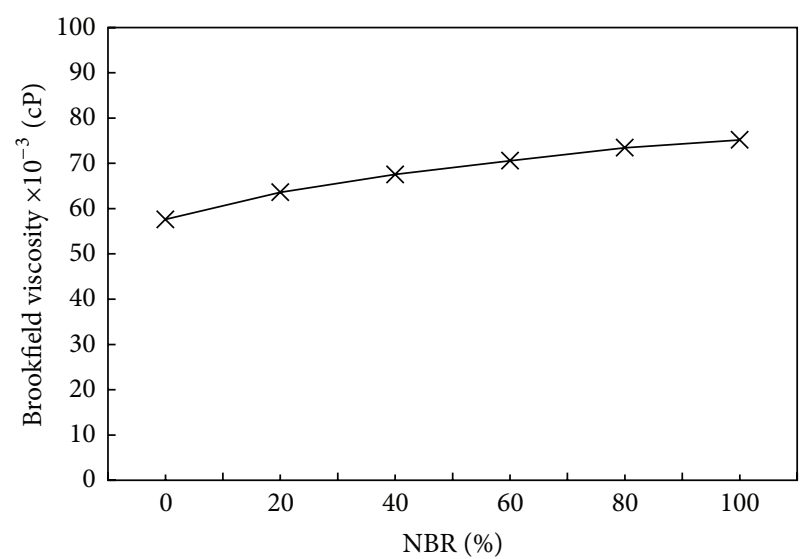

FIGURE 1: Variation of viscosity with \% NBR for NBR/SMR L blendbased adhesive.

adhesive was coated from the end of PET film at a coating area of $10 \mathrm{~cm} \times 4 \mathrm{~cm}$ for various coating thickness using a SHEEN Hand Coater. The face stock was then placed on the coated PET film (base stock) before being conditioned at room temperature for 24 hours prior to testing. A Lloyd Adhesion tester operating at $30 \mathrm{~cm} / \mathrm{min}$ was used to measure the peel force of the samples. The average peeling force was determined from the three highest peaks computed from the test.

3.4. Shear Strength. The dimension of the PET film substrate was $20 \mathrm{~cm} \times 4 \mathrm{~cm}$. The substrate was coated $10 \mathrm{~cm}$ from the end of the substrate. The end of another uncoated substrate (face stock) was then laid on the coated area of the base stock. The shear sample was then conditioned at room temperature for 24 hours prior to testing on a Lloyd Adhesion Tester operating at $30 \mathrm{~cm} / \mathrm{min}$. Shear strength was expressed as the shear force per unit area of testing.

\section{Results and Discussion}

From this study, the effect of \% NBR on viscosity, tack, peel strength, and shear strength of adhesive is discussed below.

4.1. Viscosity. The dependence of viscosity adhesive on \% NBR is shown on Figure 1. From the graph, it can be clearly seen that the viscosity of adhesive increases gradually with increase in NBR content.

The lowest viscosity is recorded for the $0 \%$ NBR, that is, $100 \%$ SMR L. The increasing viscosity with \% NBR is due to the increase in NBR content which has higher viscosity than SMR L-based adhesive. Result shows that the viscosity of NBR-based adhesive is $30.5 \%$ higher than that of SMR Lbased adhesive. This means that NBR content has significant effect in the NBR/SMR L blend adhesive for higher NBR composition.

4.2. Tack. Tack may be defined as the property of material which enables it to form a bond of measurable strength 


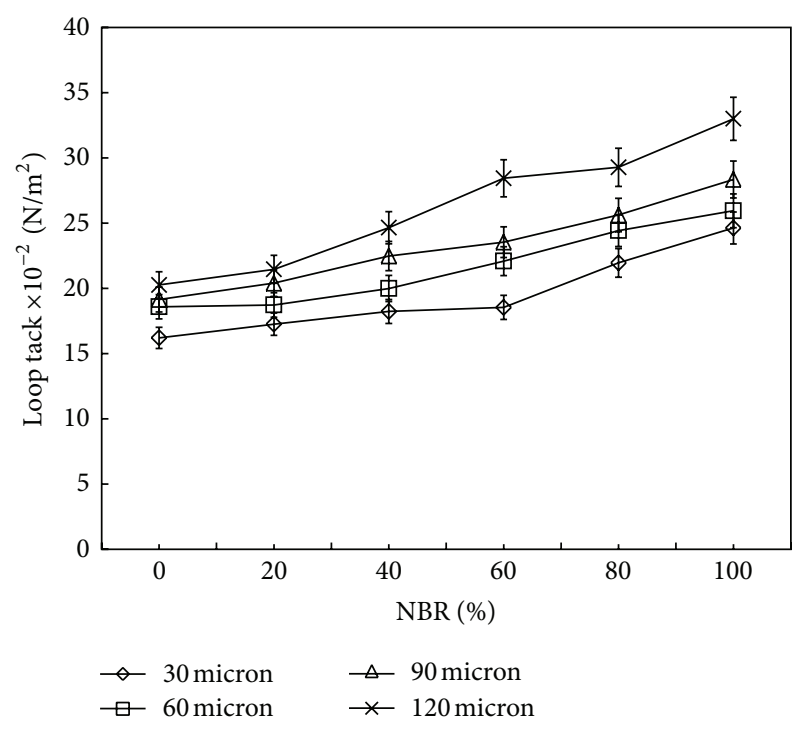

FIGURE 2: Variation of loop tack with \% NBR for NBR/SMR L blendbased adhesive at various coating thicknesses.

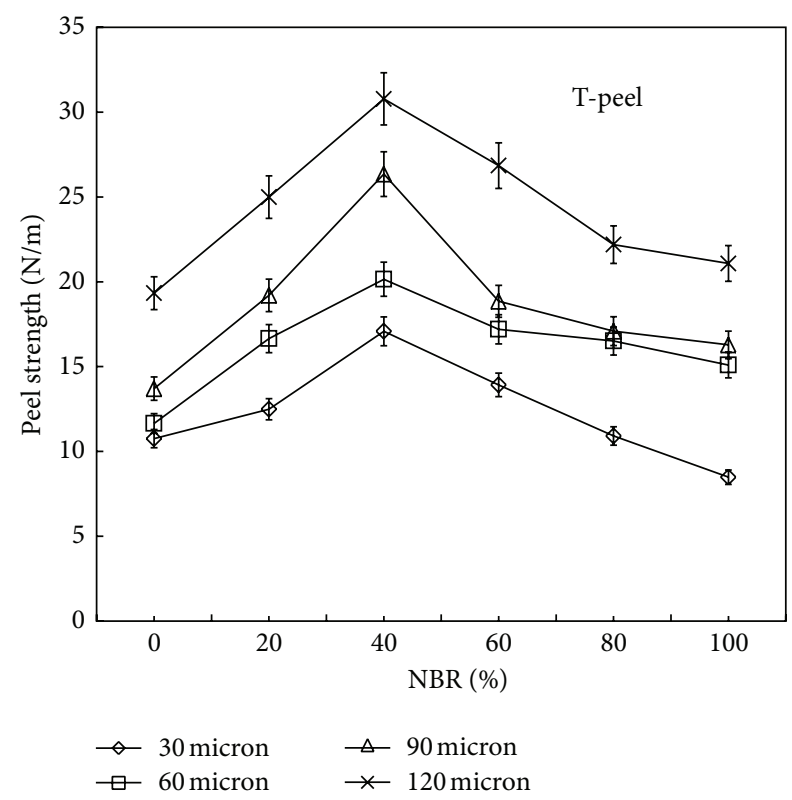

FIGURE 3: Variation of peel strength (T-peel test) with \% NBR for NBR/SMR L blend-based adhesive at various coating thicknesses.

immediately upon contact with another surface, usually with low applied pressure $[20,21]$. Figure 2 shows the effect of $\%$ NBR on the loop tack of NBR/SMR L based adhesives for various coating thickness. Loop tack increases with the increase in \% NBR blend ratio.

This observation is attributed to the increase in the degree of wettability where the adhesive is able to conform to the irregularities of the adherent; that is, low surface energy condition is observed [21]. Figure 2 also shows that tack for the $120 \mu \mathrm{m}$ coated sample is consistently higher than that of other coating thickness. This finding is associated with the higher amount of adhesive available in higher coating thickness, thus enhancing the viscoelastic response from the rubber blend.

4.3. Peel Strength. The peel strength (T-peel) of the adhesive is shown in Figure 3. For all coating thickness, peel strength indicates a maximum value at $40 \%$ NBR and drops with further increase in NBR content. The increase of peel strength up to $40 \% \mathrm{NBR}$ is associated with the increasing wettability of the adhesive on the substrate which results in the increase of mechanical interlocking and anchorage of the adhesive in pores and irregularities in the adherent $[20,22]$. However, after the optimum blend ratio, wettability decreases due to the increase in viscosity of the adhesive as $\%$ NBR is increased. Probably, the viscous adhesive hardens faster and the number of contact points with the substrate is lower, thus producing a lesser interfacial interaction [18]. Also, further increase in the blend ratio will decrease the compatibility of rubber blend as reflected by the lower peel strength as shown in Figure 3 . A similar observation is also obtained for the $90^{\circ}$ and $180^{\circ}$ peel tests, as shown in Figures 4 and 5, respectively, hence confirming the dependence of peel strength on blend ratio of NBR/SMR L adhesive. From the three modes of peel tests, maximum peel strength is observed at $40 \% \mathrm{NBR}$ at $120 \mu \mathrm{m}$ coating thickness indicating the culmination of wettability and compatibility of the adhesives. At this composition, the adhesive probably hardens at high strain levels to become a tough solid and the adhesives layer itself cannot easily be ruptured [23]; hence, the highest peel strength is observed. With respect to the effect of coating thickness on the peel strength of the NBR/SMR L adhesive, result shows that $120 \mu \mathrm{m}$ coated sample has the highest peel strength for all the three modes of peel tests as shown in Figure 6. Generally, peel strength increases with increasing adhesive thickness up to certain limit, and further increase with increasing adhesive thickness does not increase resistance to peel [21]. Increasing the adhesive thickness causes the shift from cohesive to adhesive failure where it is associated with the transition from viscous-like liquid to rubber-like elastic behaviour [24]. Figure 6 also reveals that the $90^{\circ}$ peel test consistently gives the highest peel strength followed by $180^{\circ}$ and T-peel test.

This observation is attributed to the angle of testing which suggests that $90^{\circ}$ test requires higher peeling force to separate the mechanical interlocking and anchorage of the adhesion in pores and irregularities in the substrate [20,22].

4.4. Shear Strength. Figure 7 shows the dependence of shear strength on \% NBR for various coating thicknesses. The plot indicates that shear strength increases gradually with \% NBR, an observation which is attributed to increasing cohesive and adhesive strength which enhances the shear resistance of the adhesive. For a fixed \% NBR, shear strength increases with coating thickness as shown in Figure 8. This observation is associated with the increasing amount of adhesive present in the coating layer which increases both the cohesive and adhesive strength of adhesive, thus enhancing the shear resistance of the adhesive as coating thickness increased. The rate of increase in shear strength is higher from 30 to $60 \mu \mathrm{m}$. After $60 \mu \mathrm{m}$ coating thickness, gradual increase 


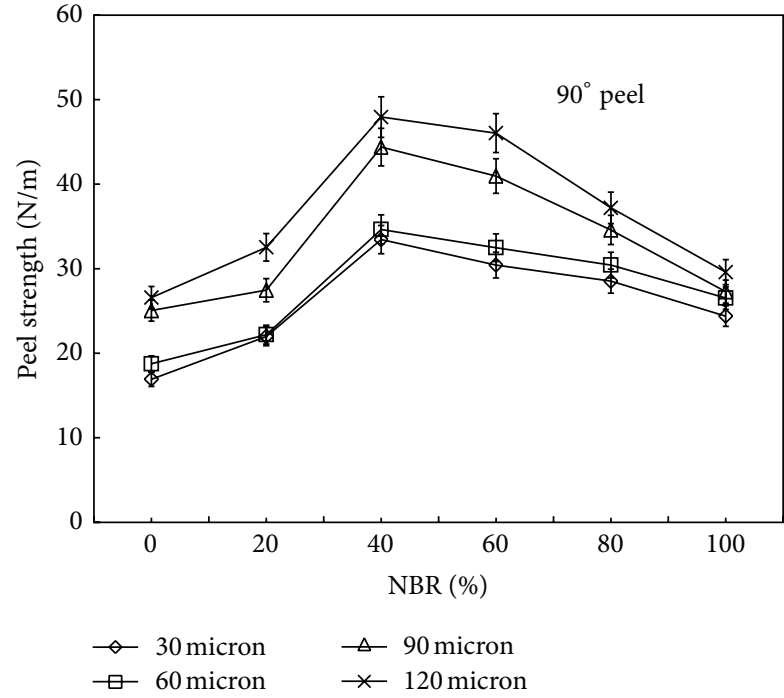

FIGURE 4: Variation of peel strength $\left(90^{\circ}\right.$ peel test) with $\%$ NBR for NBR/SMR L blend-based adhesive at various coating thicknesses.

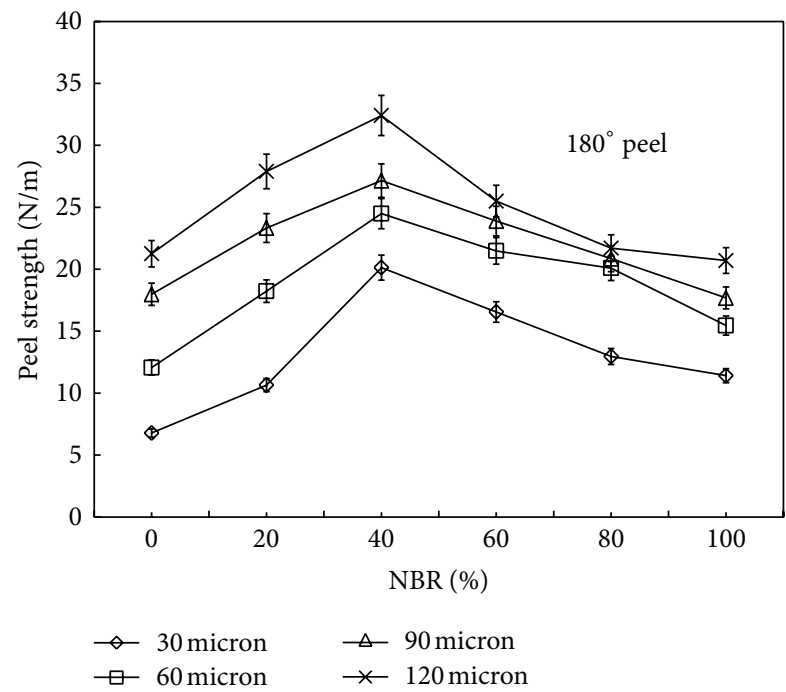

FIGURE 5: Variation of peel strength $\left(180^{\circ}\right.$ peel test) with $\%$ NBR for NBR/SMR L blend-based adhesive at various coating thicknesses.

in shear strength with coating thickness is obtained. This observation is ascribed to the transition from cohesive to adhesive failure as discussed earlier on the effect of coating thickness on the peel strength. As coating thickness exceeds $60 \mu \mathrm{m}$, adhesive failure dominates the failure mode in the shear strength determination.

\section{Conclusion}

The viscosity of NBR/SMR L based adhesive increases with increasing NBR content, an observation which is attributed to the higher viscosity of NBR based adhesive. Loop tack also increases with increase in NBR content. This observation is associated with the increase in wettability where the adhesive

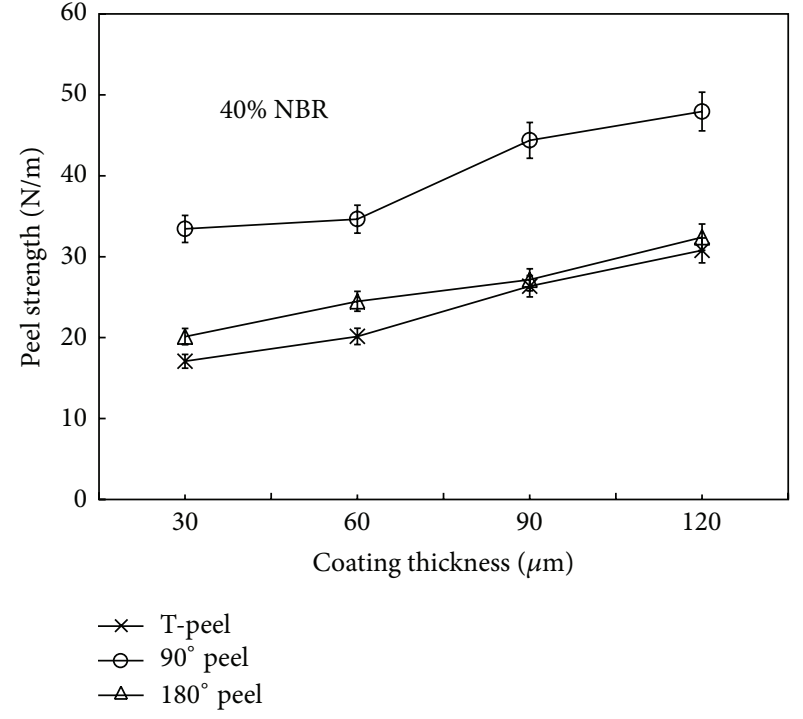

Figure 6: Dependence of peel strength on coating thickness for various modes of peel tests.

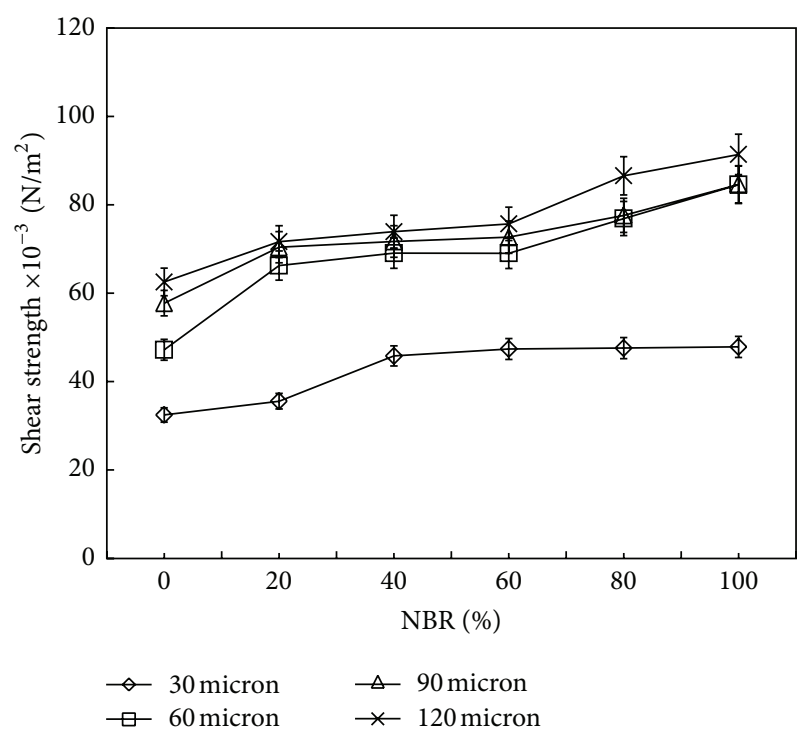

FIGURE 7: Variation of shear strength with \% NBR for NBR/SMR L blend-based adhesive at various coating thicknesses.

is able to conform to the irregularities of the adherent. For the shear strength, the increase is primarily attributed to the increase in cohesive and adhesive strength of the blend adhesive. However, peel strength indicates a maximum value at $40 \%$ NBR content due to the culmination of wettability of adhesive which results in mechanical interlocking and anchorage of the adhesive in the pore and irregularities in the adherent. In all cases, the adhesion property increases with coating thickness. This phenomenon is associated with the presence of higher amount of adhesive which enhances the viscoelastic response of the blend adhesive. 


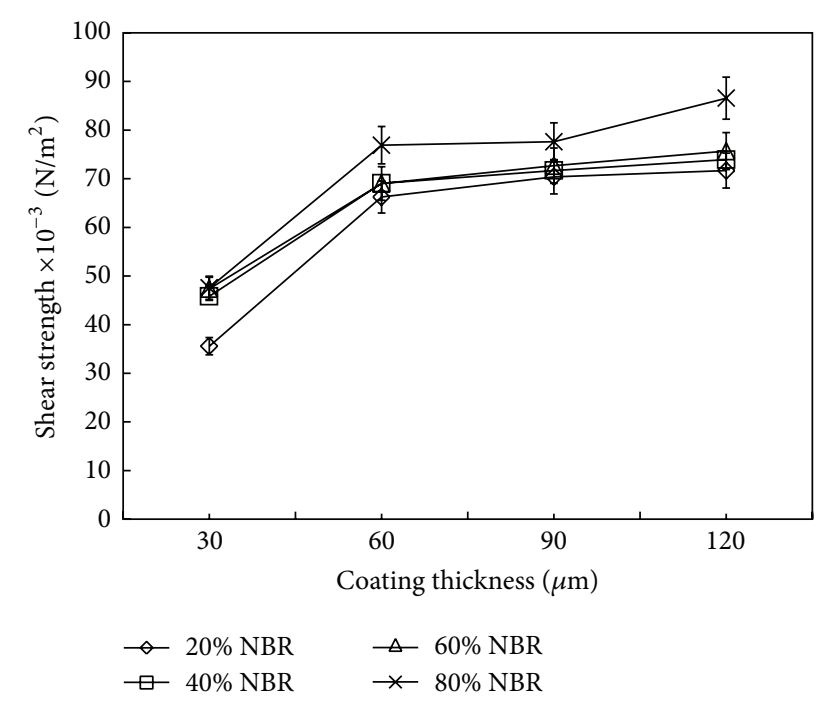

FIGURE 8: Dependence of shear strength on coating thickness for various $\%$ NBR.

\section{Conflict of Interests}

The authors declare that there is no conflict of interests regarding the publication of this paper.

\section{Acknowledgment}

The authors acknowledge the Science Fund provided by the Ministry of Science, Technology, and Innovation (MOSTI), Malaysia for this study.

\section{References}

[1] Y. C. Leong, L. M. S. Lee, and S. N. Gan, "The viscoelastic properties of natural rubber pressure-sensitive adhesive using acrylic resin as a tackifier," Journal of Applied Polymer Science, vol. 88, no. 8, pp. 2118-2123, 2003.

[2] M. Fujita, M. Kajiyama, A. Takemura, H. Ono, H. Mizumachi, and S. Hayashi, "Effects of miscibility on peel strength of natural-rubber-based pressure-sensitive adhesives," Journal of Applied Polymer Science, vol. 70, no. 4, pp. 777-784, 1998.

[3] M. Fujita, A. Takemura, H. Ono, M. Kajiyama, S. Hayashi, and H. Mizumachi, "Effects of miscibility and viscoelasticity on shear creep resistance of natural-rubber-based pressuresensitive adhesives," Journal of Applied Polymer Science, vol. 75, no. 12, pp. 1535-1545, 2000.

[4] D. J. Yarusso, "Quantifying the relationship between peel and rheology for pressure sensitive adhesives," Journal of Adhesion, vol. 70, no. 3-4, pp. 299-320, 1999.

[5] J. Du, D. D. Lindeman, and D. J. Yarusso, "Modeling the peel performance of pressure-sensitive adhesives," Journal of Adhesion, vol. 80, no. 7, pp. 601-612, 2004.

[6] A. Thitithammawong, N. Ruttanasupa, and C. Nakason, "Preparation and properties of chlorinated epoxidised natural rubber latex and its latex-based adhesive," Journal of Rubber Research, vol. 15, no. 1, pp. 19-34, 2012.
[7] L. A. Varghese and E. T. Thachil, "Studies on the adhesive properties of neoprene-phenolic blends," Journal of Adhesion Science and Technology, vol. 18, no. 2, pp. 181-193, 2004.

[8] J. P. Phillips, X. Deng, R. R. Stephen et al., "Nano- and bulk-tack adhesive properties of stimuli-responsive, fullerenepolymer blends, containing polystyrene-block-polybutadieneblock-polystyrene and polystyrene-block-polyisoprene-blockpolystyrene rubber-based adhesives," Polymer, vol. 48, no. 23, pp. 6773-6781, 2007.

[9] J. P. Phillips, X. Deng, M. L. Todd et al., "Singlet oxygen generation and adhesive loss in stimuli-responsive, fullerenepolymer blends, containing polystyrene-block-polybutadieneblock- polystyrene and polystyrene-block-polyisoprene-blockpolystyrene rubber-based adhesives," Journal of Applied Polymer Science, vol. 109, no. 5, pp. 2895-2904, 2008.

[10] W. Smitthipong, M. Nardin, J. Schultz, and K. Suchiva, "Adhesion and self-adhesion of immiscible rubber blends," International Journal of Adhesion and Adhesives, vol. 29, no. 3, pp. 253258, 2009.

[11] M. M. Magida, Y. H. Gad, and H. H. El-Nahas, "The use of compatible blend of styrene-vinylacetate copolymer/natural rubber latex in pressure-sensitive adhesive applications by using irradiation and chemical initiation," Journal of Applied Polymer Science, vol. 114, no. 1, pp. 157-165, 2009.

[12] S. A. da Silva, C. L. Marques, and N. S. M. Cardozo, "Composition and performance of styrene-isoprene-styrene (SIS) and styrene-butadiene-styrene (SBS) hot melt pressure sensitive adhesives," Journal of Adhesion, vol. 88, no. 2, pp. 187-199, 2012.

[13] J.-H. Kim, H.-G. Kim, J.-C. Lim, K.-S. Cho, and K.-E. Min, "Thermal properties and adhesion strength of amorphous $\operatorname{poly}(\alpha$-olefins) /styrene-ethylene-butylene copolymer/terpene hot-melt adhesive," Journal of Applied Polymer Science, vol. 124, no. 4, pp. 3312-3319, 2012.

[14] W. Pichayakorn, J. Suksaeree, P. Boonme, W. Taweepreda, and G. C. Ritthidej, "Preparation of deproteinized natural rubber latex and properties of films formed by itself and several adhesive polymer blends," Industrial \& Engineering Chemistry Research, vol. 51, pp. 13393-13404, 2012.

[15] S. A. Riyajan and N. Phewkeaw, "Modification of skim rubber blended with poly (vinyl alcohol) to be applied as a biodegradable pressure-sensitive adhesive: effect of 2,6-di-tbutyl-4-methylphenol and hydrocarbon resin," Rubber Chemistry and Technology, vol. 85, no. 4, pp. 547-558, 2012.

[16] S. A. Riyajan, N. Phupewkeaw, S. Maneechay, and A. Kowalczyk, "An emulsion from green epoxidized skim rubber blended with poly(vinyl alcohol) for use as a bioadhesive," International Journal of Adhesion and Adhesives, vol. 45, pp. 84-89, 2013.

[17] B. T. Poh and L. N. Ong, "Adhesion properties of styrenebutadiene rubber (SBR)/Standard Malaysian Rubber (SMR L)based adhesives in the presence of phenol formaldehyde resin," EXPRESS Polymer Letters, vol. 1, no. 10, pp. 654-659, 2007.

[18] B. T. Poh and S. S. Heng, "Effect of blend ratio on adhesion properties of pressure-sensitive adhesives prepared from SBR/SMR L blends," Polymer - Plastics Technology and Engineering, vol. 47, no. 3, pp. 325-329, 2008.

[19] B. T. Poh and A. L. Lim, "Adhesion properties of pressuresensitive adhesives prepared from SMR 10/ENR 25, SMR 10/ENR 50, and ENR 25/ENR 50 blends," Journal of Applied Polymer Science, vol. 109, no. 1, pp. 115-119, 2008.

[20] G. Gierenz and W. Karmann, Eds., Adhesives and Adhesive Tapes, Wiley-VCH, New York, NY, USA, 2001. 
[21] D. Satas, Ed., Handbook of Pressure Sensitive Adhesive Technology, Van Nostrand Reinhold, New York, NY, USA, 1982.

[22] L. H. Lee, Adhesive Bonding, Plenum Press, New York, NY, USA, 1991.

[23] I. Skeist, Ed., Handbook of Adhesives, Van Nostrand Reinhold, New York, NY, USA, 3rd edition, 1990.

[24] B. T. Poh and C. L. Chee, "Effect of coumarone-indene resin on adhesion property of SMR 20-based pressure-sensitive adhesives," International Journal of Polymeric Materials, vol. 56, no. 3, pp. 247-255, 2007. 

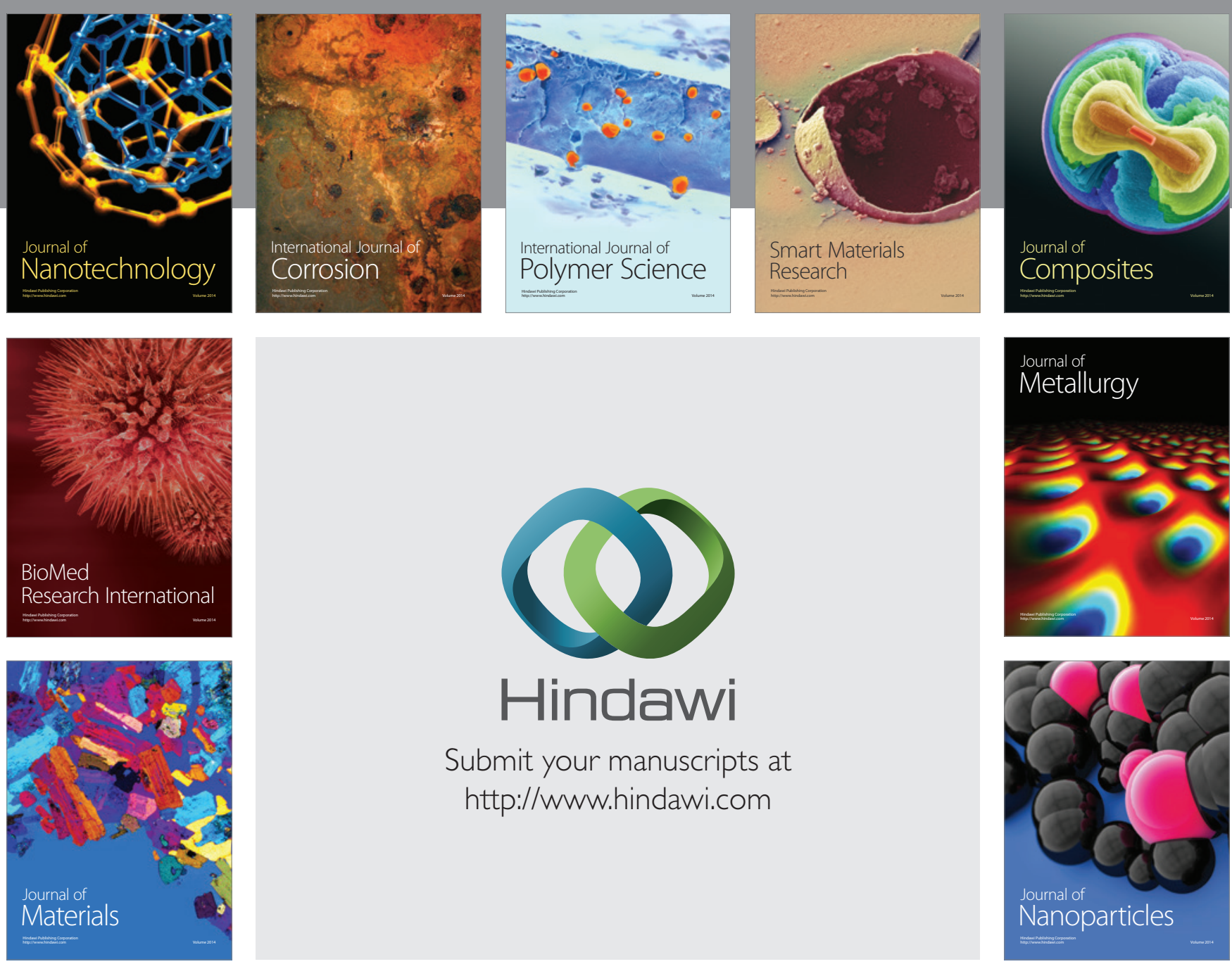

Submit your manuscripts at http://www.hindawi.com
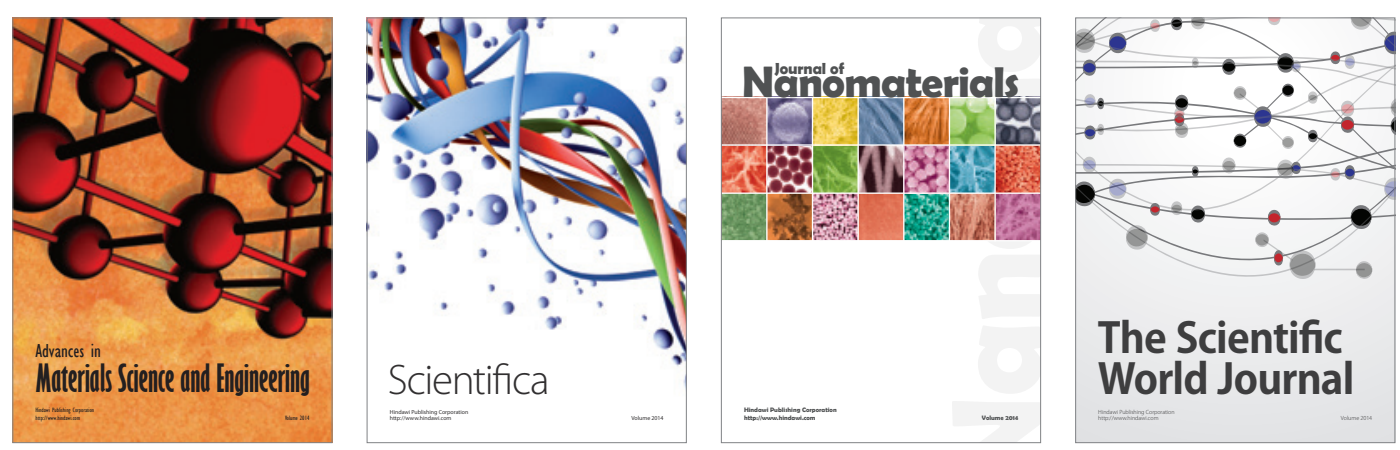

\section{The Scientific World Journal}
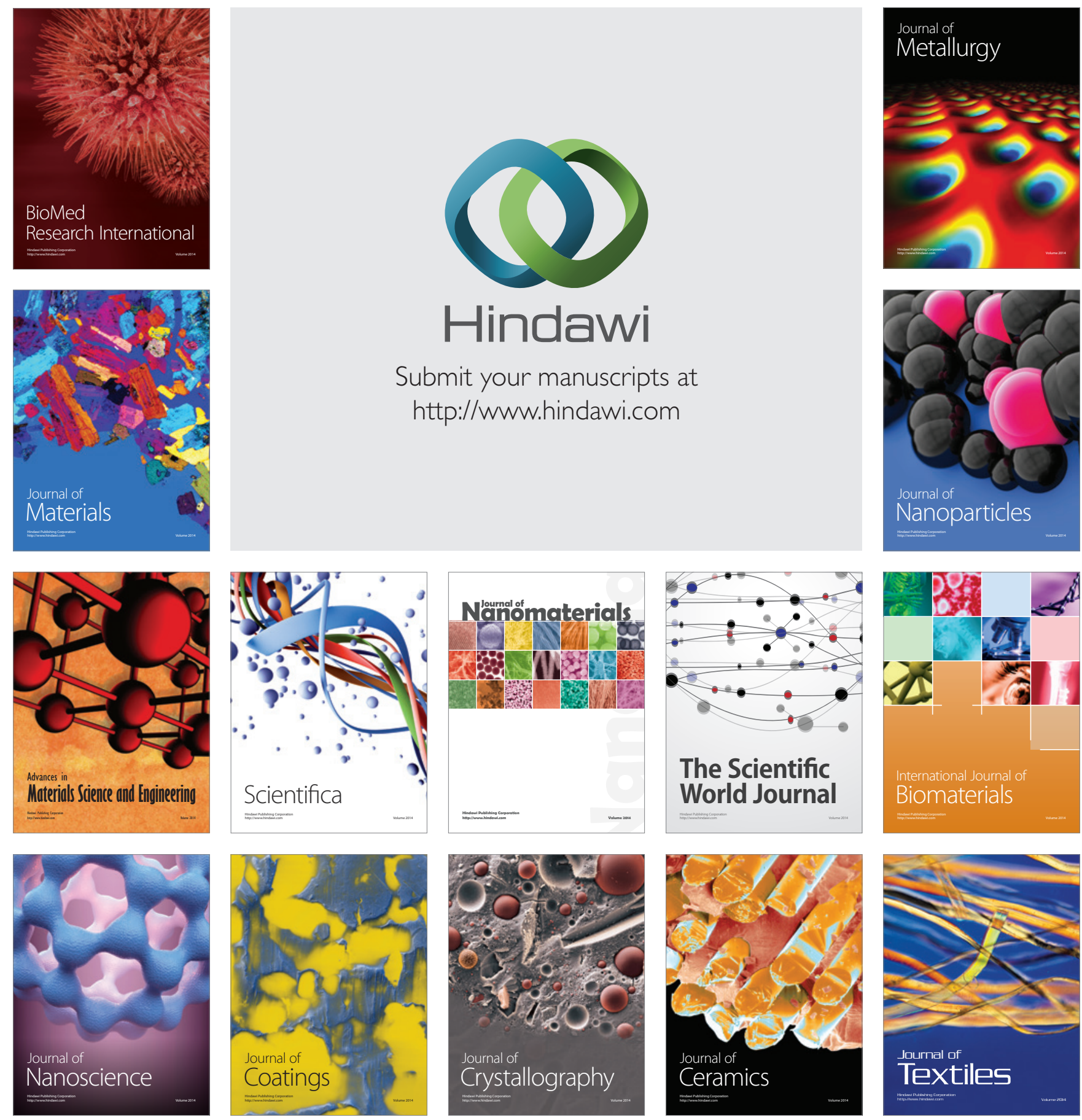